\title{
Short communication: Assessment of the potential of cinnamaldehyde, condensed tannins, and saponins to modify milk fatty acid composition of dairy cows ${ }^{1}$
}

\author{
C. Benchaar*2 and P. Y. Chouinard $†$ \\ *Agriculture and Agri-Food Canada, Dairy and Swine Research and Development Centre, Sherbrooke, QC, Canada J1M 1 Z3 \\ †Département des Sciences Animales, Université Laval, Québec, QC, Canada G1V 0A6
}

\section{ABSTRACT}

This study was conducted to determine whether feeding cinnamaldehyde (main component of cinnamon bark essential oil; Cinnamon cassia), condensed tannins from quebracho trees (Schinopsis balansae), or saponins from Yucca schidigera altered the milk fatty acid profile of dairy cows. For this purpose, 4 lactating cows were used in $4 \times 4$ Latin square design (28-d period) and fed a total mixed ration containing no additive (control), or supplemented with cinnamaldehyde $(1 \mathrm{~g} / \mathrm{d}$; CIN $)$, quebracho condensed tannin extract $(150 \mathrm{~g} / \mathrm{d} ; 70 \%$ of tannins; QCT), or Yucca schidigera saponin extract (60 $\mathrm{g} / \mathrm{d} ; 10 \%$ of saponins; YSE). Results revealed no effects of feeding CIN or QCT on milk fatty acid profile. Supplementation with YSE resulted in some modifications of milk fatty acid profile as suggested by the reduced proportions of C6:0 (2.71 vs. 2.95\%), C8:0 (1.66 vs. $1.89 \%$ ), and trans-11 C18:1 (0.92 vs. 1.01\%). Results show low potential of cinnamaldehyde, condensed tannins, and saponins to alter ruminal biohydrogenation process and modify the fatty acid profile of milk fat at the feeding rates used in this study. Further investigations are needed to determine the factors that limit the effects of these secondary metabolites on ruminal microbial populations involved in the biohydrogenation processes of unsaturated fatty acids.

Key words: plant extract, milk fatty acid, dairy cow

Over the last decade, a considerable amount of research work has been devoted to enriching the milk of dairy cows with potentially health-promoting fatty acids such as conjugated linoleic acids (CLA), which have been shown in several animal studies to contribute to cancer prevention, decreased atherosclerosis, improved immune response, and altered energy metabolism (Jen-

\footnotetext{
Received February 6, 2009.

Accepted March 21, 2009.

${ }^{1}$ Contribution number 996 from the Dairy and Swine Research and Development Centre, PO Box 90, STN-Lennoxville, Sherbrooke, Quebec, Canada J1M 1 Z3.

${ }^{2}$ Corresponding author: Chaouki.Benchaar@agr.gc.ca
}

kins et al., 2008). The most common CLA isomer is the cis-9, trans-11 C18:2, which is formed in the rumen during biohydrogenation of dietary linoleic acid (cis-9, cis-12 C18:2) or in body tissue by $\Delta^{9}$-desaturase from vaccenic acid (trans-11 C18:1), another intermediate in ruminal biohydrogenation (Bauman et al., 2003).

Different dietary approaches have been used to enhance the concentrations of CLA in milk fat of dairy cows such as feeding free plant oils or oils seeds (Dhiman et al., 2000), fish oil (Chouinard et al., 2001), or algae (Franklin et al., 1999). Supplementation with ionophores such as monensin has also been shown to decrease the rate of ruminal biohydrogenation of unsaturated fatty acids in vitro (Fellner et al., 1997) and increase the content of CLA in milk fat (AlZahal et al., 2008). Plant secondary metabolites such as essential oils have been suggested as a potential means to manipulate bacterial populations involved in ruminal biohydrogenation to modify the fatty acid composition of ruminant-derived food products such as milk and meat. For instance, Durmic et al. (2008) observed that ethanolic extracts and essential oils from some Australian plants selectively inhibited the growth of pure cultures of some bacteria (e.g., Clostridium proteoclasticum) involved in ruminal biohydrogenation and that some inhibited the saturation of linoleic acid and other intermediates such as CLA and vaccenic acid in batch culture incubations. This observation demonstrated the potential of plant secondary metabolites to increase the output of CLA and vaccenic acid from the rumen, and to enhance the concentrations of these unsaturated fatty acids in ruminant-derived food products. Using a continuous culture fermenter system, Lourenço et al. (2008) showed that some essential oil compounds such as cinnamaldehyde (3-fenil-2-propenal phenol; $\mathrm{C}_{9} \mathrm{H}_{8} \mathrm{O}$ ) caused a shift from the major biohydrogenation pathway to a secondary biohydrogenation pathway of C18:2 as evidenced by the higher proportions of trans-10 C18:1 and trans-10, cis-12 CLA in the fermenter effluent. However, in vitro screening batch culture techniques have limitations because of the difficulty of simulating the diversity and dynamics of mixed ruminal bacteria 
(Durmic et al., 2008). On the other hand, data from the study of Lourenço et al. (2008) were obtained using a continuous culture fermenter maintained at constant $\mathrm{pH}(6.4 \pm 0.05)$, which is useful to isolate $\mathrm{pH}$ effects but is not representative of in vivo conditions where the $\mathrm{pH}$ is subject to diurnal variation (Nocek, 1992). Several in vitro (Troegeler Meynadier et al., 2003; AbuGhazaleh et al., 2005) and in vivo (Kalscheur et al., 1997; Kucuk et al., 2001) studies showed that ruminal $\mathrm{pH}$ plays an important role in lipolysis and biohydrogenation of unsaturated fatty acids. Using a continuous culture fermenter under uncontrolled $\mathrm{pH}$ conditions, Loor et al. (2003) demonstrated that changes in $\mathrm{pH}$ substantially affected the extent of biohydrogenation of fatty acids in orchardgrass and red clover. Moreover, Cardozo et al. (2005) in a batch culture incubation study showed that the effects of essential oils and their main constituents, including cinnamaldehyde, on rumen microbial fermentation are $\mathrm{pH}$ dependent. At $\mathrm{pH} 5.5$, cinnamaldehyde increased total VFA concentration and decreased the acetate to propionate ratio. However, at $\mathrm{pH} 7.0$, cinnamaldehyde exerted the opposite effect, decreasing total VFA concentration and increasing the acetate to propionate ratio. Taken together, these considerations suggest that conclusions drawn from in vitro studies should be interpreted with caution, and ultimately, in vivo animal research is needed to assess the potential of plant extracts and secondary metabolites to alter processes involved in ruminal biohydrogenation to modify the fatty acid profile of ruminant products such as milk. Thus, this work is a contribution to provide new information in this research area by investigating the effects of feeding 3 secondary metabolites: cinnamaldehyde (main component of cinnamon bark essential oil; Cinnamon cassia), saponins from Yucca schidigera, and condensed tannins from quebracho extract (Schinopsis balansae) on the fatty acid profile of milk fat of dairy cows. Results presented in this short communication were generated from the analyses of milk samples collected from the same experiment conducted to determine the effects of cinnamaldehyde, quebracho condensed tannin, and Yucca schidigera saponin on digestion, ruminal fermentation characteristics, and milk production (Benchaar et al., 2008).

Four lactating Holstein cows fitted with ruminal cannulas (10 cm, Bar Diamond Inc., Parma, ID) were used in a $4 \times 4$ Latin square design (28-d periods) balanced for residual effects. The cows averaged $87 \pm 29$ DIM, $35.6 \pm 3.1 \mathrm{~kg} / \mathrm{d}$ of milk, and $730 \pm 89 \mathrm{~kg}$ of BW at the start of the experiment. They were housed in individual tie stalls and had continual access to water during the experiment. Cows were fed twice daily (0800 and 1600 h) for ad libitum intake ( 5 to $10 \%$ orts, on an as-fed basis) a TMR (Table 1) containing no additive (control),
Table 1. Ingredients and fatty acid composition of the TMR fed to dairy cows

\begin{tabular}{lc}
\hline Item & \\
\hline Ingredient, \% of DM & \\
Grass silage & 39.6 \\
Corn, ground & 15.9 \\
Beet pulp, dehydrated & 12.0 \\
Corn gluten meal & 9.9 \\
Wheat bran & 9.8 \\
Soybean meal, 48\% CP & 8.8 \\
Sodium bicarbonate & 1.5 \\
Limestone & 1.1 \\
Ca 17\%: P 21\% & 0.6 \\
Salt ${ }^{1}$ & 0.4 \\
Magnesium oxide & 0.3 \\
Vitamin A, D, and E premix ${ }^{2}$ & 0.2 \\
Selenium & 0.04 \\
Fatty acids, g of identified fatty acids $/ \mathrm{kg}$ of DM & \\
C14:0 $16: 0$ & 0.51 \\
C18:0 0 & 3.52 \\
cis-9 C18:1 & 0.61 \\
cis-11 C18:1 & 2.92 \\
cis-9, cis-12 C18:2 & \\
cis-9, cis-12, cis-15 C18:3 & 0.22 \\
Cotal fatty acids 0 & 5.53 \\
\hline
\end{tabular}

${ }^{1}$ Contained (per kg): $965 \mathrm{~g}$ of $\mathrm{NaCl}, 7,500 \mathrm{mg}$ of $\mathrm{Zn}, 5,000 \mathrm{mg}$ of $\mathrm{Mn}$, $2,500 \mathrm{mg}$ of $\mathrm{Cu}, 1,600 \mathrm{mg}$ of $\mathrm{Fe}, 70 \mathrm{mg}$ of I, and $40 \mathrm{mg}$ of Co.

${ }^{2}$ Contained (per kg): 500,000 IU of vitamin A, 50,000 IU of vitamin D, and $550 \mathrm{IU}$ of vitamin E.

or supplemented with cinnamaldehyde $(1 \mathrm{~g} / \mathrm{d}$; CIN), quebracho condensed tannin extract (150 g/d; QCT), or Yucca schidigera saponin extract $(60 \mathrm{~g} / \mathrm{d}$; YSE). Cinnamaldehyde ( $\geq 98 \%$ purity) was provided by Phodé (Albi, France), quebracho extract (containing $70 \%$ of condensed tannins) by Unitan (Buenos Aires, Argentina), and Yucca schidigera extract (DK sarasponin 30, containing $10 \%$ of steroidal saponins) by Desert King International (San Diego, CA). The appropriate amount of each additive for each cow was weighed daily and mixed thoroughly into a portion of the TMR to ensure consumption of the entire dose. Cows were milked twice daily in their stalls (0500 and $1700 \mathrm{~h}$ ) and milk samples were collected from 4 consecutive milkings (d 22 to 23 ), pooled on milk-yield basis, and stored at $-80^{\circ} \mathrm{C}$ until analyzed for fatty acid composition. Cows were cared for in accordance with the guidelines of the Canadian Council on Animal Care (1993).

For analysis of milk fatty acids, methyl esters were prepared by base-catalyzed transmethylation according to the method of Chouinard et al. (1997). Composition of fatty acids in ground TMR samples was determined according to the procedure of Sukhija and Palmquist (1988). Fatty acid analyses were carried out with a gas chromatograph (HP 5890A Series II, Hewlett Packard, Palo Alto, CA) equipped with a 100-m CP-Sil 88 capillary column (i.d., $0.25 \mathrm{~mm}$; film thickness, $0.20 \mu \mathrm{m}$; 
Chrompack, Middelburg, the Netherlands) and a flameionization detector as described previously (Farnworth et al., 2007).

The data were analyzed as a $4 \times 4$ Latin square design using the MIXED procedure of SAS (SAS Institute Inc., Cary, NC). The model included treatment and period as fixed effects and cow as a random effect. The residual effect was initially included in the model but it was removed because it was not significant. Differences between treatments and the control were declared significant at $P \leq 0.05$ using Dunnett's comparison test, and trends were discussed at $0.05<P \leq 0.10$ unless otherwise stated.

Results presented in Table 2 show that the addition of CIN to the diet did not change the proportions of individual milk fatty acids. These results contrast with those of Lourenço et al. (2008) who observed that supplying CIN at $500 \mathrm{mg} / \mathrm{L}$ in a dual-flow continuous culture fermenter maintained at constant $\mathrm{pH}$ affected the process of biohydrogenation of forage (i.e., Lolium perenne) polyunsaturated fatty acids. Supplementation with CIN in that study inhibited the apparent biohydrogenation of C18:2 (linoleic acid) and C18:3 (linolenic acid) as reflected by the accumulation of intermediates such as trans-10 C18:1, trans-10, cis-12 C18:2, and trans-11, cis-15 C18:2. The discrepancy between our study and that of Lourenço et al. (2008) may be due to the different dosage level of CIN used. The maximum ruminal concentration of CIN used in the present experiment was estimated at $10 \mathrm{mg} / \mathrm{L} \mathrm{(100}$ $\mathrm{L}$ of rumen volume; $1 \mathrm{~g} / \mathrm{d}$ fed), which is well below the concentration of $500 \mathrm{mg} / \mathrm{L}$ used in the in vitro study of Lourenço et al. (2008). Such ruminal concentrations (i.e., $500 \mathrm{mg} / \mathrm{L}$ ) are higher than likely to occur in vivo and would correspond to impractical feeding rates that, if applied, would adversely affect the efficiency of rumen microbial fermentation, feed digestibility, and animal performance. Indeed, in the study of Lourenço et al. (2008), the use of cinnamaldehyde at a dose of $500 \mathrm{mg} / \mathrm{L}$ caused a strong inhibition of the microbial activity as reflected by the large decrease $(-63 \%)$ of total VFA concentration, which suggests a reduction on overall diet fermentability. This suggests that caution must be taken in extrapolating in vitro results to in vivo conditions. In vitro techniques are useful in terms of screening plant extracts for antimicrobial effects, but the ultimate value of these compounds must be assessed in vivo. The lack of effects of CIN observed in this study may be due to the adaptation of rumen microbes to CIN. Indeed, it is apparent from several continuous culture studies that rumen microbes are able to adapt, particularly when essential oils are administered at low doses (e.g., Cardozo et al., 2004: $0.22 \mathrm{mg} / \mathrm{L}$; Busquet et al., 2005b: $2.2 \mathrm{mg} / \mathrm{L}$ ). It seems that adaptation does not occur at high doses (Busquet et al., 2005a: $300 \mathrm{mg} / \mathrm{L}$; Fraser et al., 2007: $500 \mathrm{mg} / \mathrm{L}$ ), but again it is unlikely that such ruminal concentrations of essential oils could be achieved under normal feeding rate conditions.

Supplementation with YSE resulted in some modifications of milk fatty acid profile as suggested by the decreased proportions of C6:0 (2.71 vs. $2.95 \% ; P=$ $0.10), \mathrm{C} 8: 0$ (1.66 vs. $1.89 \% ; P=0.08)$, and trans -11 C18:1 (0.92 vs. 1.01\%; $P=0.05$ ). Saponin from Yucca schidigera showed no effect on the rate of $\alpha$-linolenic acid biohydrogenation when supplied at the rate of $1.12 \%$ of dietary DM in a Rusitec system (Khiaosa-Ard et al., 2009). Using another source of saponins (terpene saponin from Quillaja saponaria), Lourenço et al. (2008) also observed no changes in fatty acid profile of ruminal fluid in continuous culture fermenters supplied with high doses (500 or 1,000 mg/L) of Quillaja saponaria (containing $25 \%$ of sapogenin). Collectively, these results suggest that the potential of saponin to alter ruminal microbial populations involved in biohydrogenation of unsaturated fatty acids is limited or nonexistent. Moreover, the possible adaptation of rumen microbial populations to saponin and their ability to convert it to sapogenin (Newbold et al., 1997; Teferedegne et al., 1999) may further limit the effects of these secondary metabolites on rumen processes.

Milk fatty acid composition was not affected by feeding QCT (Table 2). There is limited information on the use of condensed tannins to alter the ruminal biohydrogenation process and manipulate the fatty acid profile of ruminant-derived food products (i.e., milk or meat). Condensed tannins have been shown to inhibit the growth of Butyrivibrio fibrisolvens (Jones et al., 1994), one of the bacterial species involved in ruminal biohydrogenation of fatty acids. Using $24-h$ in vitro batch culture incubations, Kronberg et al. (2007) observed that the addition of quebracho condensed tannin $(20 \mathrm{~g} / 100 \mathrm{~g}$ of flaxseed) reduced biohydrogenation of C18:3 in flaxseed (13 vs. $43 \%$ ). However, despite this reduction, feeding tannin-treated flaxseed to beef cattle in the same study did not increase the concentrations of C18:3 in plasma neutral lipids. Results from the study of Kronberg et al. (2007) indicate the need for caution when interpreting results from in vitro experiments. In fact, some studies (Makkar, 2003) suggest that microbial populations are able to adapt to tannins, which may explain the discrepancy between in vitro and in vivo studies. Using the Rusitec system, Khiaosa-Ard et al. (2009) reported an inhibition of the last step of C18:3 ruminal biohydrogenation by condensed tannins supplied at a rate of $7.89 \%$ of dietary DM. This inhibition led to the accumulation of trans-11 C18:1 in the feed residues but had no effect on the losses of C18:3 compared with the control treatment. The level of con- 
Table 2. Milk fatty acid profile (g/100 g of total fatty acids) of cows fed a TMR without supplementation (control), or supplemented with cinnamaldehyde (CIN), quebracho condensed tannin extract (QCT), or Yucca schidigera saponin extract (YSE)

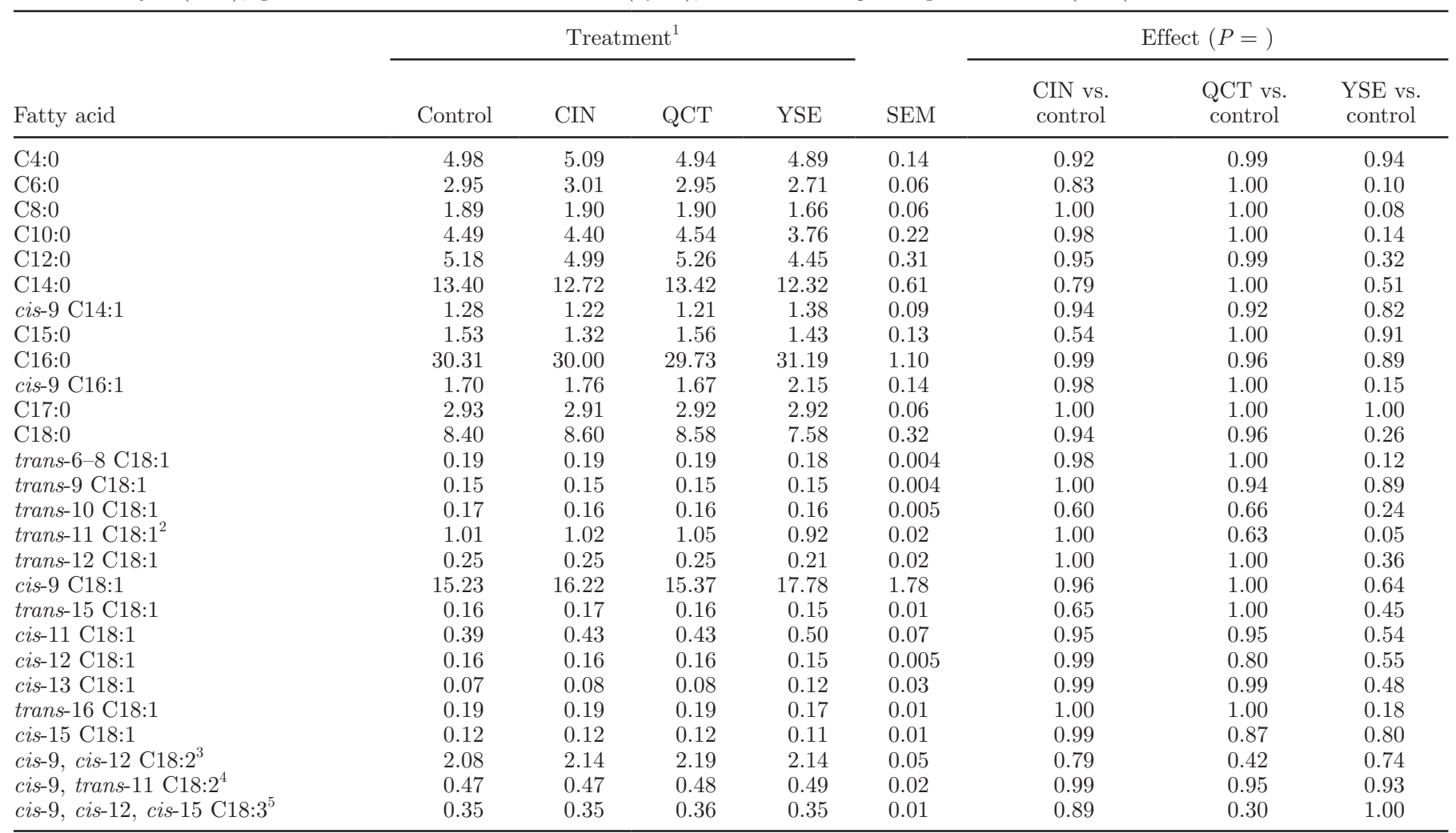

${ }^{1}$ Cinnamaldehyde was fed at $1 \mathrm{~g} / \mathrm{d}$, quebracho condensed tannin extract at $150 \mathrm{~g} / \mathrm{d}$, and Yucca schidigera saponin extract at $60 \mathrm{~g} / \mathrm{d}$.

${ }^{2}$ Vaccenic acid.

${ }^{3}$ Linoleic acid.

${ }^{4}$ Conjugated linoleic acid.

${ }^{5} \alpha$-Linolenic acid.

densed tannins used in the study by Khiaosa-Ard et al. (2009) was 18 times higher than that fed in the current study $(0.45 \%$ of DMI), which may explain differences in response to tannin supplementation between the two studies. However, such a high level (i.e., 7.89\%) is impractical in terms of feeding because of the potential deleterious effects on diet digestibility as evidenced by the reduction in nutrient digestibility $(\mathrm{OM}, \mathrm{CP}, \mathrm{NDF}$, ether extract) reported in the study by Khiaosa-Ard et al. (2009).

Results from the present study show no effects of feeding cinnamaldehyde $(1 \mathrm{~g} / \mathrm{d})$ or condensed tannin from quebracho trees $(150 \mathrm{~g} / \mathrm{d})$ on milk fatty acid profile, whereas feeding saponins from Yucca schidigera (60 $\mathrm{g} / \mathrm{d}$ ) resulted in minor modifications of milk fatty acid composition. These findings reveal the low potential of cinnamaldehyde, condensed tannins, and saponins to alter the ruminal biohydrogenation process and modify the fatty acid profile of milk fat when these extracts are used at practical feeding rates in dairy cow diets.

\section{ACKNOWLEDGMENTS}

The authors thank Lisa Croteau (Dairy and Swine Research and Development Centre, Sherbrooke, QC, Canada) for planning and executing this study; Micheline Gingras (Département des Sciences Animales, Université Laval, Québec, QC, Canada) for fatty acid analyses; and the barn staff of the Dairy and Swine Research and Development Centre (Sherbrooke, QC, Canada) for their contribution to the present study. Provision of quebracho extract by Unitan (Buenos Aires, Argentina), Yucca schidigera extract by Desert King International (San Diego, CA), and cinnamaldehyde by Phodé (Albi, France) is gratefully acknowledged. This study was financially supported by Agriculture and Agri-Food Canada.

\section{REFERENCES}

AbuGhazaleh, A. A., M. B. Riley, E. E. Thies, and T. C. Jenkins. 2005. Dilution rate and $\mathrm{pH}$ effects on the conversion of oleic acid 
to trans $\mathrm{C}_{18: 1}$ positional isomers in continuous culture. J. Dairy Sci. 88:4334-4341.

AlZahal, O., N. E. Odongo, T. Mutsvangwa, M. M. Or-Rashid, T. F. Duffield, R. Bagg, P. Dick, G. Vessie, and B. W. McBride. 2008. Effects of monensin and dietary soybean oil on milk fat percentage and milk fatty acid profile in lactating dairy cows . J. Dairy Sci. 91:1166-1174.

Bauman, D. E., B. A. Corl, and D. G. Peterson. 2003. The biology of conjugated linoleic acid in ruminants. Pages 146-173 in Advances in Conjugated Linoleic Acid Research. Vol. 2, J. L. Sébédio, W. W. Christie, and R. Adlof, ed. AOCS Press, Champaign, IL.

Benchaar, C., T. A. McAllister, and P. Y. Chouinard. 2008. Digestion, ruminal fermentation, ciliate protozoal populations, and milk production from dairy cows fed cinnamaldehyde, quebracho condensed tannin, or Yucca schidigera saponin extract. J. Dairy Sci. 91:4765-4777.

Busquet, M., S. Calsamiglia, A. Ferret, P. W. Cardozo, and C. Kamel. 2005a. Effects of cinnamaldehyde and garlic oil on rumen microbial fermentation in a dual flow continuous culture. J. Dairy Sci. 88:2508-2516.

Busquet, M., S. Calsamiglia, A. Ferret, and C. Kamel. 2005b. Screening for the effects of natural plant extracts and secondary plant metabolites on rumen microbial fermentation in continuous culture. Anim. Feed Sci. Technol. 123:597-613.

Canadian Council on Animal Care. 1993. Guide to the Care and Use of Experimental Animals. Vol. 1. E. D. Olfert, B. M Cross, and A. A. McWilliam, ed. CCAC, Ottawa, Ontario, Canada.

Cardozo, P. W., S. Calsamiglia, A. Ferret, and C. Kamel. 2004. Effects of natural plant extracts on ruminal protein degradation and fermentation profiles in continuous culture. J. Anim. Sci. 82:3230-3236.

Cardozo, P. W., S. Calsamiglia, A. Ferret, and C. Kamel. 2005. Screening for the effects of natural plant extracts at different $\mathrm{pH}$ on in vitro rumen microbial fermentation of a high-concentrate diet for beef cattle. J. Anim. Sci. 83:2572-2579.

Chouinard, P. Y., L. Corneau, W. R. Butler, Y. Chilliard, J. K. Drackley, and D. E. Bauman. 2001. Effect of dietary lipid source on conjugated linoleic acid concentrations in milk fat. J. Dairy Sci. 84:680-690.

Chouinard, P. Y., J. Lévesque, V. Girard, and G. J. Brisson. 1997. Dietary soybeans extruded at different temperatures: Milk composition and in situ fatty acid reactions. J. Dairy Sci. 80:2913-2924.

Dhiman, T. R., L. D. Satter, M. W. Pariza, M. P. Galli, K. Albright, and M. X. Tolosa. 2000. Conjugated linoleic acid (CLA) content of milk from cows offered diets rich in linoleic and linolenic acid. J. Dairy Sci. 83:1016-1027.

Durmic, Z., C. S. McSweeney, G. W. Kemp, P. Hutton, R. J. Wallace, and P. E. Vercoe. 2008. Australian plants with potential to inhibit bacteria and processes involved in ruminal biohydrogenation of fatty acids. Anim. Feed Sci. Technol. 145:271-284.

Farnworth, E. R., P. Y. Chouinard, H. Jacques, S. Venkatramanan, A. A. Mafu, S. Defnoun, and P. Jones. 2007. The effect of drinking milk containing conjugated linoleic acid on fecal microbiological profile, enzymatic activity, and fecal characteristics in humans. Nutr. J. 6:1-15.

Fellner, V., F. D. Sauer, and J. K. G. Kramer. 1997. Effect of nigericin, monensin, and tetronasin on biohydrogenation in continuous flowthrough ruminal fermentors. J. Dairy Sci. 80:921-928.

Franklin, S. T., K. R. Martin, R. J. Baer, D. J. Schingoethe, and A. R. Hippen. 1999. Dietary marine algae (Schizochytrium sp.) increases concentrations of conjugated linoleic, docosahexaenoic and trans vaccenic acids in milk of dairy cows. J. Nutr. 129:2048-2052.
Fraser, G. R., A. V. Chaves, Y. Wang, T. A. McAllister, K. A. Beauchemin, and C. Benchaar. 2007. Assessment of the effects of cinnamon leaf oil on rumen microbial fermentation using two continuous culture systems. J. Dairy Sci. 90:2315-2328.

Jenkins, T. C., R. J. Wallace, P. J. Moate, and E. E. Mosley. 2008. Recent advances in biohydrogenation of unsaturated fatty acids within the rumen microbial ecosystem. J. Anim. Sci. 86:397412.

Jones, G. A., T. A. McAllister, K.-J. Cheng, and A. D. Muir. 1994. Effect of sainfoin (Onobrychris viciifolia Scop.) condensed tannins on growth and proteolysis by 4 strains of rumen bacteria. Appl. Environ. Microbiol. 60:1374-1378.

Kalscheur, K. F., B. B. Teter, L. S. Piperova, and R. A. Erdman. 1997. Effect of dietary forage concentration and buffer addition on duodenal flow of trans- $\mathrm{C}_{18: 1}$ fatty acids and milk fat production in dairy cows. J. Dairy Sci. 80:2104-2114.

Khiaosa-Ard, R., S. F. Bryner, M. R. L. Scheeder, H. R. Wettstein, F. Leiber, M. Kreuzer, and C. R. Soliva. 2009. Evidence for the inhibition of the terminal step of ruminal $\alpha$-linolenic acid biohydrogenation by condensed tannins. J. Dairy Sci. 92:177188.

Kronberg, S. L., E. J. Scholljegerdes, G. Barceló-Coblijn, and E. J. Murphy. 2007. Flaxseed treatments to reduce biohydrogenation of alpha-linolenic acid by rumen microbes in cattle. Lipids 42:11051111.

Kucuk, O., B. W. Hess, P. A. Ludden, and D. C. Rule. 2001. Effect of forage:concentrate ratio on ruminal digestion and duodenal flow of fatty acids in ewes. J. Anim. Sci. 79:2233-2240.

Loor, J. J., W. H. Hoover, T. K. Miller-Webster, J. H. Herbein, and C. E. Polan. 2003. Biohydrogenation of unsaturated fatty acids in continuous culture fermenters during digestion of orchardgrass or red clover with three levels of ground corn supplementation. J. Anim. Sci. 81:1611-1627.

Lourenço, M., P. W. Cardozo, S. Calsamiglia, and V. Fievez. 2008. Effects of saponins, quercetin, eugenol, and cinnamaldehyde on fatty acid biohydrogenation of forage polyunsaturated fatty acids in dual-flow continuous culture fermenters. J. Anim. Sci. 86:30453053.

Makkar, H. P. S. 2003. Effects and fate of tannins in ruminant animals, adaptation to tannins, and strategies to overcome detrimental effects of feeding tannin-rich feeds. Small Rumin. Res. 49:241256.

Newbold, C. J., S. M. El Hassan, J. Wang, M. E. Ortega, and R. J. Wallace. 1997. Influence of foliage from African multipurpose trees on activity of rumen protozoa and bacteria. Br. J. Nutr. $78: 237-249$.

Nocek, J. E. 1992. Feeding sequence and strategy effects on ruminal environment and production performance in first lactation cows. J. Dairy Sci. 75:3100-3108.

Sukhija, P. S., and D. L. Palmquist. 1988. Rapid method for determination of total fatty acid content and composition of feedstuffs and feces. J. Agric. Food Chem. 36:1202-1206.

Teferedegne, B., F. McIntosh, P. O. Osuji, A. Odenyo, R. J. Wallace, and C. J. Newbold. 1999. Influence of foliage from different accessions of the sub-tropical leguminous tree, Sesbania sesban, on ruminal protozoa in Ethiopian and Scottish sheep. Anim. Feed Sci. Technol. 78:11-20.

Troegeler-Meynadier, A., M. C. Nicot, C. Bayourthe, R. Moncoulon, and F. Enjalbert. 2003. Effects of $\mathrm{pH}$ and concentrations of linoleic and linolenic acids on extent and intermediates of ruminal biohydrogenation in vitro. J. Dairy Sci. 86:4054-4063. 